CYSTIC FIBROSIS

\title{
Peak oxygen uptake and mortality in children with cystic fibrosis
}

\author{
P Pianosi, J LeBlanc, A Almudevar
}

Thorax 2005;60:50-54. doi: 10.1136/thx.2003.008102

See end of article for authors' affiliations

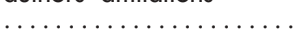

Correspondence to: Dr P Pianosi, Respirology Clinic, IWK Health Centre, P O Box 3070, Halifax, Canada B3J 3G9; ppianosi@dal.ca

Received 17 June 2003

Accepted 1 August 2004

\begin{abstract}
Background: Single measurements of peak oxygen uptake $\left(\mathrm{V}_{2}\right)$ have been shown to predict mortality in patients with cystic fibrosis (CF) although no longitudinal study of serial measurements has been reported in children. A study was undertaken to determine whether the initial, final, or the rate of fall of forced expiratory volume in 1 second $\left(\mathrm{FEV}_{1}\right)$ or peak $\dot{\mathrm{V}}_{2}$ was a better predictor of mortality.

Methods: Twenty eight children aged 8-17 years with CF performed annual pulmonary function and maximal exercise tests over a 5 year period to determine $\mathrm{FEV}_{1}$ and peak $\dot{\mathrm{V}}_{2}$, magnitude of their change over time, and survival over the subsequent 7-8 years. Analysis was done using Kaplan-Meier curves and Cox proportional hazard model.

Results: Peak $\mathrm{VO}_{2}$ fell during the observation period in $70 \%$ of the patients, with a mean annual decline of $2.1 \mathrm{ml} / \mathrm{min} / \mathrm{kg}$. Initial peak $\mathrm{VO}_{2}$ was not predictive of mortality but rate of decline and final peak $\dot{\mathrm{VO}}_{2}$ of the series were significant predictors. Patients with peak $\dot{V}_{2}$ less than $32 \mathrm{ml} / \mathrm{min} / \mathrm{kg}$ exhibited a dramatic increase in mortality, in contrast to those whose peak $\mathrm{VO}_{2}$ exceeded $45 \mathrm{ml} / \mathrm{min} / \mathrm{kg}$, none of whom died. The first, last, and rate of decline in $\mathrm{FEV}_{1}$ over time were all significant predictors of mortality. Conclusions: Higher peak $\mathrm{VO}_{2}$ is a marker for longer survival in $\mathrm{CF}$ patients.
\end{abstract}

$M$ uch of what we know about exercise in children with cystic fibrosis (CF) has come from cross sectional studies ${ }^{1-6}$ which essentially conclude that lower forced expiratory volume in 1 second $\left(\mathrm{FEV}_{1}\right)$ and reduced weight for height or lean body mass are correlated with lower peak oxygen uptake (peak $\dot{\mathrm{V}}_{2}$ ), and that peak $\dot{\mathrm{V}}_{2}$ could predict earlier mortality. ${ }^{7}{ }^{8}$ Nixon et al reported that higher peak $\dot{\mathrm{V}}_{2}$ was significantly correlated with survival, and that $\mathrm{FEV}_{1}$ did not improve the correlation in a multivariate model. Moorcroft et al ${ }^{8}$ reported that, while peak $\dot{\mathrm{V}}_{2}$ correlated with survival, it was no better than $\mathrm{FEV}_{1}$ in predicting likelihood of survival over 5 years. One problem with such studies of lung function and exercise capacity is the variable time of onset and rate of progression of clinically significant pulmonary disease within an individual. Thus, single time point measurements are more susceptible to bias inherent to this approach, a bias precluded by longitudinal studies. There is a remarkable dearth of data regarding longitudinal assessment of peak $\dot{\mathrm{V}}_{2}$ in children with $\mathrm{CF}$. 9 One study in young adults with $\mathrm{CF}$ reported that peak $\mathrm{V}_{2}$ remained stable despite a fall in mean predicted $\mathrm{FEV}_{1}$ from $69 \%$ to $54 \%$, based on two measurements of peak $\dot{\mathrm{V}}_{2}$ on average 6.3 years apart in a study with a high patient attrition rate. ${ }^{10}$

Such longitudinal data are of particular interest because they may offer insight into understanding the relationship between fitness and survival in CF-the "nature versus nurture" argument. Presently, it is recognised that there are "milder CF phenotypes" depending on the class of mutation and the presence or absence of pancreatic insufficiency. ${ }^{11}$ Selvadurai et al ${ }^{12}$ recently demonstrated a relationship between genotype and peak aerobic power. Do patients who inherently possess greater maximum aerobic power live longer, or do patients with milder phenotype remain more active and simply maintain a higher peak $\mathrm{V}_{2}$ rather than let it fall due to debility? Determination of peak $\dot{\mathrm{V}}_{2}$ embodies the consummate test of oxygen transport and utilisation, and is heavily dependent on optimal cardiopulmonary function. Thus, peak $\dot{\mathrm{V}}_{2}$ could provide another yardstick for measuring severity of the CF phenotype, for assessing response to intervention(s), or for predicting mortality as has been demonstrated in $\mathrm{CF}$ and chronic obstructive pulmonary disease (COPD). ${ }^{13}$

A prospective annual assessment of peak $\dot{\mathrm{V}}_{2}$ was therefore carried out from 1991 to 1996 on a convenience sample of children with CF. The aims were to track pulmonary function and nutritional status - the two main predictors of peak $\dot{\mathrm{V}}_{2}$ derived from cross sectional studies-in order to determine the importance of peak $\dot{\mathrm{V}}_{2}$ in the prediction of mortality in $\mathrm{CF}$. This would indicate whether or not peak $\dot{\mathrm{V}}_{2}$ is a good predictor of mortality over a 5-10 year period and, if so, whether the actual innate level or the change over time is more important.

\section{METHODS \\ Subjects}

The study cohort consisted of children with CF followed regularly (usually quarterly) at the CF clinic of the Winnipeg Health Sciences Center. This institution is the sole tertiary care centre for children in the province of Manitoba (population $\sim 1$ million), Canada, and virtually all children in the province with CF were followed there. Eligible patients were those old enough to perform a progressive exercise test $(\geqslant 7$ years old) of any severity except transplant candidates. No patients with cor pulmonale or on supplemental oxygen were included in the study. A necessary condition for testing at a scheduled clinic appointment was that the patient was in his/her usual clinical status-that is, with no recent exacerbation. Colonisation with Burkholderia cepacia was very uncommon among patients attending this clinic. Treatment remained essentially unchanged during the study period despite the introduction of Pulmozyme, which was used sporadically in the clinic. All eligible patients underwent annual testing. As far as possible, the test was incorporated and presented to the families as part of the routine clinical assessment. Sometimes scheduling difficulties made it impossible to adhere to the annual testing ideal, so test results obtained as part of other research studies (with a formal consent process) were used in the analysis. At all 
times procedures conformed to ethical standards of the local Institutional Review Board and were explained to parents and patients, all of whom assented.

\section{Protocol}

FEV $_{1}$ was measured (model AT-6, Schiller AG) and expressed as percentage predicted. ${ }^{14}$ Nutritional status was assessed by ideal weight for actual height. ${ }^{15}$ Exercise testing was done on an electrically braked cycle ergometer (Lode Excalibur). Subjects performed progressive exercise with step increments of 5,10 , or 15 watts per minute, based on standing height and severity of pulmonary disease, such that expected duration of exercise would be approximately 10 minutes. Flexibility in pedal cadence of $40-80 \mathrm{rpm}$ was permitted. They were strongly encouraged to pedal to exhaustion, manifest by falling pedal cadence accompanied by visible signs of exertion.

\section{Apparatus and measurements}

Heart rate was measured with a standard tripolar ECG (HP 78203A). Ventilation was measured with a screen pneumotachograph and exhaled gases were collected in 100 litre gas collection bags on a Jaeger Transferscreen II modified to perform exercise studies. Exhaled gases were continuously analysed for oxygen and carbon dioxide concentrations using Ametek zirconium oxide (S-3A) and infrared (CD-3A) analysers, respectively. Oxygen saturation was measured by pulse oximetry (Nellcor N-200, Hayward, CA, USA) using an earclip probe. All signals were continuously recorded on a strip chart recorder (Gould TA2000) running at $5 \mathrm{~mm} / \mathrm{s}$ for offline computation of ventilation, oxygen uptake and carbon dioxide output based on mixed expired gas concentrations using the Haldane transformation. The highest oxygen uptake in the progressive test was taken as peak $\dot{\mathrm{V}}_{2}$.

\section{Statistical analysis}

Measurements were made from 1991 to 1996 and the last known follow up was January 2004. Peak $\dot{\mathrm{V}}_{2}$ was normalised for body weight $(\mathrm{ml} / \mathrm{min} / \mathrm{kg})$. The rise in peak $\dot{\mathrm{V}}_{2}$ values in the majority of subjects after the first test was immediately obvious. We therefore decided to exclude the first test result in all subjects, thereby reducing our sample size since analysis was limited to patients who completed at least four exercise tests. Mortality was defined as death or date of lung transplant since those who received a lung transplant would have died shortly without this procedure. In 7 years following the last test (1996), six patients died from their CF lung disease, one of them 2 years after transplantation. Another three patients were still alive following lung transplantation but were considered to be imminent deaths, bringing the total number of pulmonary related deaths in this cohort to nine.

We began by fitting a linear regression to the time series for $\mathrm{FEV}_{1}$ and for peak $\mathrm{VO}_{2}$ of each patient. Because we were interested in factors affecting the change in peak $\dot{\mathrm{VO}}_{2}$ over time, we also employed a mixed effects model analysis using Splus 2000 version 3 (Mathsoft Inc). Cox proportional hazard regression was done to determine the influence of $\mathrm{FEV}_{1}$ and peak $\dot{V}_{\mathrm{O}_{2}}$ on mortality. We chose the intercept of the timeseries regression as the initial measurement of each predictor in the series, and the final measurement was taken as the de facto last test result in the series. Kaplan-Meier curves were constructed from these variables. We also examined whether the change over time was a better predictor than a single measurement using the time gradients calculated as described above. The model fit was tested with the likelihood ratio statistic. ${ }^{16}$ Hazard ratios and $95 \%$ confidence intervals were computed for $\mathrm{FEV}_{1}$ and peak $\dot{\mathrm{V}}_{2}$ as predictors using Cox proportional hazard regression. These analyses were done with Statview version 5 (SAS Institute Inc) on a Macintosh computer.

\section{RESULTS}

Although approximately 75 patients were followed through the clinic, the number of patients who performed exercise tests was limited as nearly half were too young to reliably perform spirometry and progressive exercise. Three patients aged $>7$ years were never tested because they died during the first few years of the study, and two more died after having done only one maximal test during the study period. Eight children were tested twice and nine children were tested only once, thus yielding an insufficient number of tests to be included in the analysis. Among this group, mean (SD) FEV $_{1}$ was 79 (19)\% predicted. The cohort consisted of 28 children ( 14 boys) who were tested on at least four occasions, yielding at least three measurements (after discarding the first test) per patient between December 1991 and April 1996 (table 1).

Pulmonary function in the study population spanned the spectrum from normal to severe airway obstruction. The overall decline in $\mathrm{FEV}_{1}$ during the study period averaged 8.3\% predicted, yielding a mean annual rate of fall of approximately $2.5 \%$ predicted $(\mathrm{p}=0.0013)$. Patients achieved a heart rate $>170 / \mathrm{min}$ in all exercise tests and most achieved a heart rate of $>180 / \mathrm{min}$ at maximal exercise. The mean ratio of maximal ventilation to maximum voluntary ventilation $\left(35 \times \mathrm{FEV}_{1}\right)$ for each patient over the course of the study was 0.928 and ranged from a low of 0.463 to a high of 1.46 . Significant oxygen desaturation $(<90 \%)$ was not seen in any patient. The mean time elapsed between tests was 1.2 years (range 0.3-3) and time between initial and final tests used in these analyses ranged from 0.9 to 4.3 (mean 2.3) years. Patients grew an average of $4.3 \mathrm{~cm}$ per year in height (range $1-8$ ) and gained an average weight of $3.6 \mathrm{~kg}$ per year (range 0.8-9) during the course of the study. They were well nourished: mean percent ideal body weight was 103 at the initial test, with no patient less than $80 \%$; while the mean percent ideal body weight at the time of the final test was 102. In general, percent ideal body weight remained very stable during the observation period.

The mixed effects model demonstrated an overall decline in peak $\dot{\mathrm{V}}_{2}$ of $0.17 \mathrm{ml} / \mathrm{min} / \mathrm{kg}$ per month which was equal in boys and girls although boys started with a slightly higher peak $\dot{\mathrm{VO}}_{2}$ (mean difference $\left.3.7 \mathrm{ml} / \mathrm{min} / \mathrm{kg}, \mathrm{p}=0.0035\right)$. In addition to the influence of sex, the model also showed a significant interaction between age and months elapsed since initial testing, with a more rapid decline $(p=0.048)$ in children who were older at the onset of annual testing. There was no relation between initial peak $\dot{\mathrm{V}}_{2}$ and the subsequent rate of decline.

The Cox proportional hazards model summaries are shown in table 2. The hazard ratios can be interpreted as the increase (or decrease) in the hazard ratio with an increase in one unit of the predictor variable: in the case of $\mathrm{FEV}_{1}$, the unit is $1 \%$ predicted whereas in the case of peak $\dot{V}_{2}$ the unit is $1 \mathrm{ml} /$ $\mathrm{min} / \mathrm{kg}$. The hazard ratios indicate a lower risk of death in the follow up period in patients with higher $\mathrm{FEV}_{1}$ or peak $\dot{\mathrm{V}}_{2}$. Final but not initial peak $\dot{\mathrm{V}}_{2}$ measurement in an individual was highly predictive of mortality in the 8 years following cessation of data collection, as shown by a Kaplan-Meier plot (fig 1).

In order to determine whether any single measurement was a better predictor of mortality than a series of annual measurements, time gradients were calculated for $\mathrm{FEV}_{1}$ and for peak $\dot{\mathrm{V}}_{2}$ and the slopes of these functions were used as covariates in a Cox regression model. The results of this analysis and the corresponding hazard ratios are shown in the lower part of table 2 and the units are change in percent 
Table 1 Initial and final anthropometric and spirometric variables for the cohort of 28 children

\begin{tabular}{|c|c|c|c|c|}
\hline & \multicolumn{2}{|l|}{ Initial } & \multicolumn{2}{|l|}{ Final } \\
\hline & Mean & Range & Mean & Range \\
\hline Age (years) & 10 & $7-16$ & 13 & $9-18$ \\
\hline Height $(\mathrm{cm})$ & 139 & $122-171$ & 153 & $137-177$ \\
\hline Weight (kg) & 35 & $24-79$ & 47 & $30-77$ \\
\hline IBW (\%) & 103 & $81-164$ & 103 & $84-161$ \\
\hline $\mathrm{FEV}_{1}(\%$ pred $)$ & 81 & $33-137$ & 73 & $28-125$ \\
\hline Peak $\mathrm{VO}_{2}(\mathrm{ml} / \mathrm{min} / \mathrm{kg})$ & 41.2 & $24.7-60.6$ & 37.2 & $18.6-55.2$ \\
\hline
\end{tabular}

predicted $\mathrm{FEV}_{1}$ or change in peak $\dot{\mathrm{V}}_{2}(\mathrm{ml} / \mathrm{min} / \mathrm{kg})$ per month. According to these survival functions, the hazard rate was roughly equivalent for both $\mathrm{FEV}_{1}$ and peak $\dot{\mathrm{V}}_{2}$ intercepts. This is not surprising since these measurements were taken, in many cases, as much as 10 years earlier. On the other hand, the rate of change in $\mathrm{FEV}_{1}$ and peak $\dot{\mathrm{V}}_{2}$ during the course of the study exerted small but significant effects on ultimate mortality. The smallness of values for the hazard ratios coupled with their relatively large standard error hinders conceptualisation, so these data are best portrayed as in fig 2. Although age and sex did not contribute significantly to the Cox regression analysis, they are also highlighted in the figures to show their known effect on mortality. There was a clustering of mortality in the FEV 1 plot in a manner that makes intuitive sense: either a low initial $\mathrm{FEV}_{1}$ with little change thereafter or a high initial $\mathrm{FEV}_{1}$ with an obvious subsequent slide were both associated with mortality in our cohort (fig 2A). The same pattern, though present, is not as readily apparent in the peak $\dot{\mathrm{V}}_{2}$ plot (fig 2B). Nevertheless, in light of the Kaplan-Meier curves shown in fig 1 , we constructed a third plot of the rate of change of peak $\dot{\mathrm{V}}_{2}$ versus final peak $\dot{\mathrm{VO}}_{2}$ (fig 3). Among those who died during the follow up period, there was a clustering toward lower peak $\dot{\mathrm{V}}_{2}$ values and none exhibited an upward trend in peak $\dot{\mathrm{V}}_{2}$ during the testing period.

\section{DISCUSSION}

Our longitudinal analysis of a sample of children with CF confirmed the prognostic value of peak $\dot{\mathrm{VO}}_{2}$ with results strikingly similar to those of Nixon et al. ${ }^{7}$ Patients whose final peak $\dot{\mathrm{V}}_{2}$ was in the lowest tertile had a mortality rate approaching $60 \%$ over the subsequent $7-8$ years. The prognostic information captured in peak $\dot{\mathrm{V}}_{2}$ was also borne out

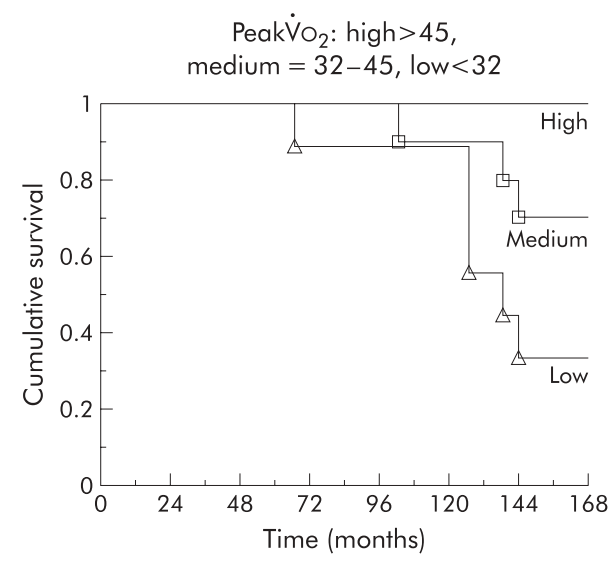

Figure 1 Kaplan-Meier plots of final peak $\mathrm{VO}_{2}$ and likelihood of survival during follow up stratified according to high, medium, and low peak $\mathrm{VO}_{2}$. The lowest tertile was peak $\mathrm{VO}_{2} \leqslant 31.99 \mathrm{ml} / \mathrm{min} / \mathrm{kg}$. by Cox regression analysis (table 2), although this was not apparent from initial peak $\dot{\mathrm{V}}_{2}$ values. According to hazard ratios computed by the Cox model, the effects of $\mathrm{FEV}_{1}$ and peak $\dot{\mathrm{V}}_{2}$ on survival were of similar magnitude, but examination of both the initial values and their respective rates of change showed the superiority of $\mathrm{FEV}_{1}$ in this regard. The fact that the rate of decline in peak $\dot{\mathrm{V}}_{2}$ was a statistically significant predictor of mortality (table 2 ) is most likely due simply to the fact that two patients with relatively high initial peak $\dot{\mathrm{V}}_{2}$ (who coincidentally had low $\mathrm{FEV}_{1}$ ) experienced greater reductions in peak $\dot{\mathrm{V}}_{2}$ during the years leading up to death or transplantation. The influence of peak $\dot{\mathrm{V}}_{2}$ (actual value or rate of change) in the prediction of mortality is best depicted in fig 3. The importance of relative underweight to prognosis in CF has been recognised, ${ }^{17}$ but our inability to demonstrate this in our survival analysis was probably due to the overall good nutritional status of the patients in this series. Although our patient population was small, the findings are made more robust by the fact that they all came from a single centre where care was standardised and where there was negligible isolation rate of $B$ cepacia.

We interpret our data as follows. Patients in our study fell into the disease severity category of those who survive beyond 15 years according to Corey et al. ${ }^{18}$ The mean age at study outset was 10 years and the study lasted for 5 years. Survival beyond this time was highly likely, and the corollary is that risk of death in that same time frame was correspondingly small. In such a population, declining $\mathrm{FEV}_{1}$ early in the course of the disease was small and had little impact on the prediction of mortality until a threshold was reached. Once this threshold was crossed, mortality within the next 7 years became more likely. At this stage peak $\dot{\mathrm{V}}_{2}$ entered the picture as a variable with predictive value for outcome: higher peak $\dot{\mathrm{V}}_{2}$ was associated with greater longevity. The fact that the rate of decline in peak $\dot{\mathrm{V}}_{2}$ in our patients was not affected by initial peak $\dot{\mathrm{V}}_{2}$ implies that those who started with a higher peak $\dot{\mathrm{V}}_{2}$ lived longer. No study published thus far was designed to answer the key question-whether better peak $\dot{V}_{O_{2}}$ is a marker for less severe illness or whether those patients who remain physically active succeed in delaying the onset of respiratory failure. It is conceivable that, as pulmonary function declines due to repeated chest exacerbations during which the child feels unwell, he/she refrains from physical activity and thus becomes progressively deconditioned. Studies of levels of habitual activity in children with CF reached various conclusions, ${ }^{19} 20$ although activity levels fell as health status declined. ${ }^{21}$ However, it is not at all clear that the level of habitual physical activity has any bearing on peak $\dot{\mathrm{V}}_{2}$ in healthy children. ${ }^{22}$

Whereas $\mathrm{FEV}_{1}$ is the usual marker for severity of lung disease, many factors other than lung function influence peak $\dot{\mathrm{V}}_{2}$. These principally include measurable factors such as height, sex, age, and pubertal status, ${ }^{23}$ as well as more difficult to quantify factors such as effort. Physical fitness 
Table 2 Univariate Cox regression functions using single predictor and time gradients of predictor variable

\begin{tabular}{|c|c|c|c|}
\hline Model predictor & Hazard ratio & p value & $95 \% \mathrm{Cl}$ \\
\hline Peak $\mathrm{V}_{2}$ intercept & 0.953 & 0.34 & 0.865 to 1.051 \\
\hline $\mathrm{FEV}_{1}$ intercept & 0.959 & 0.013 & 0.928 to 0.0991 \\
\hline Final peak $\mathrm{VO}_{2}$ & 0.845 & 0.0028 & 0.757 to 0.944 \\
\hline Final FEV & 0.928 & 0.0003 & 0.894 to 0.968 \\
\hline Peak $\mathrm{VO}_{2}$ intercept & 0.910 & 0.087 & 0.816 to 1.014 \\
\hline Peak $\mathrm{VO}_{2}$ slope & $0.048^{*}$ & 0.007 & 0.005 to 0.430 \\
\hline $\mathrm{FEV}_{1}$ intercept & 0.915 & $<0.001$ & 0.868 to 0.964 \\
\hline $\mathrm{FEV}_{1}$ slope & $0.008^{* *}$ & 0.004 & 0.0003 to 0.210 \\
\hline
\end{tabular}

also has a substantial genetic component ${ }^{24}$ and it is becoming apparent that genes remote from the CF gene locus also determine disease severity. ${ }^{25}$ This raises the possibility that the same genes that confer better physical fitness also confer a survival advantage in CF. Selvadurai et al ${ }^{12}$ recently demonstrated a relationship between genotype and peak aerobic power. One could hypothesise that patients with similar degrees of lung disease, measured by $\mathrm{FEV}_{1}$, have different prospects for survival depending on their peak $\mathrm{V}_{2}$. Figure 3 illustrates this point by contrasting two patients from the present cohort. One was a 16 year old girl of mean (SD) 83 (1)\% ideal body weight with $\mathrm{FEV}_{1}$ of 52 and $49 \%$ predicted and peak $\dot{\mathrm{V}}_{2}$ of 30 and $25 \mathrm{ml} / \mathrm{min} / \mathrm{kg} 1$ year apart who required a lung transplant within 2 years, and the other
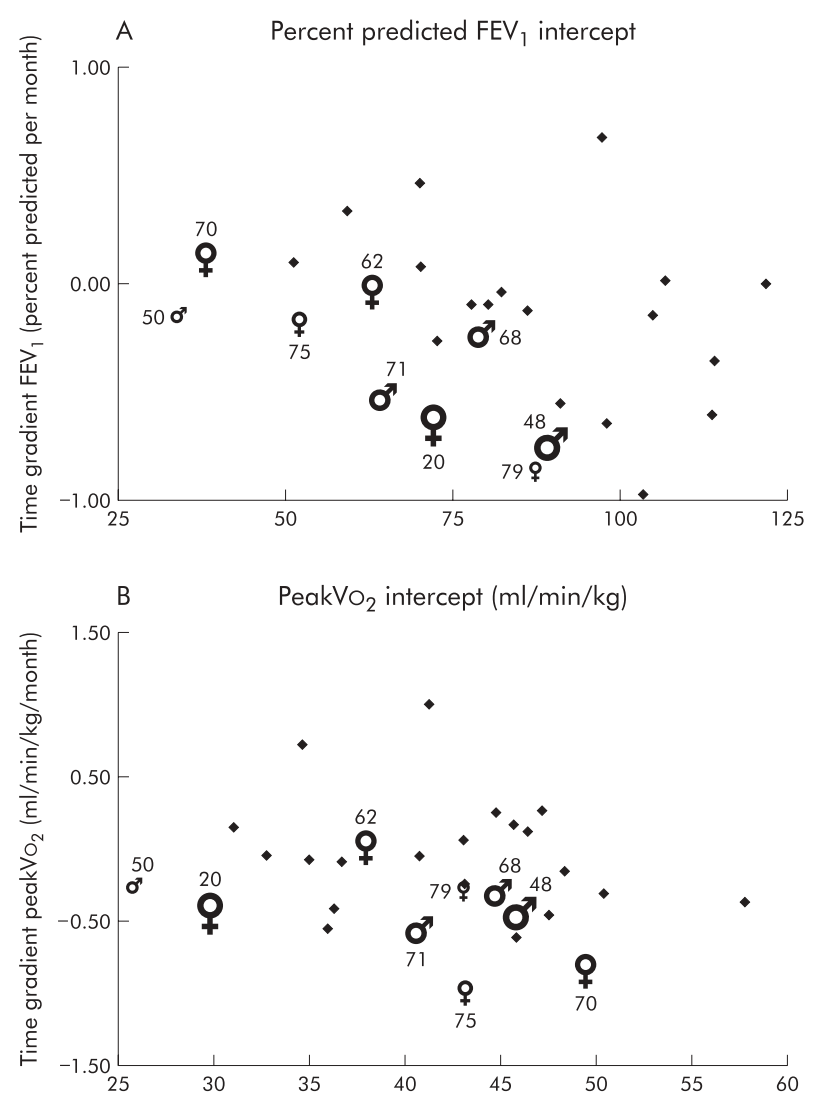

Figure 2 Plots of fitted slopes versus fitted intercepts (by linear regression) for (A) $\mathrm{FEV}_{1}$ and (B) peak $\mathrm{VO}_{2}$ of each subject in the study group. The lung deaths are shown according to sex with the size of the symbol proportional to the age of the patient at commencement of the study. The number beside each event symbol is the number of months from the last test to the time of death. was a 14 year old girl of mean (SD) 93 (1)\% ideal body weight whose $\mathrm{FEV}_{1}$ hovered between 38 and $43 \%$ predicted and whose peak $\dot{\mathrm{V}}_{2}$ was consistently $>40 \mathrm{ml} / \mathrm{min} / \mathrm{kg}$ over an 18 month period. She did not die from progressive lung disease until more than 6 years later.

It is clear that there is a learning effect in the measurement of peak $\dot{\mathrm{V}}_{2}$ in children and that the results of a single test are suspect, particularly if they are a first attempt. This should come as no surprise to the experienced clinician who knows that it typically involves more than one visit for most children to master the forced expiratory manoeuvre used in obtaining $\mathrm{FEV}_{1}$, and first attempts are often unreliable. Performing a progressive exercise test to voluntary exhaustion is more complicated still, and a child will probably perform better once he/she knows what to expect. While there was an inexorable decline in peak $\dot{\mathrm{V}}_{2}$ over time of the order of $2 \mathrm{ml} /$ $\mathrm{min} / \mathrm{kg}$ per year, some patients demonstrated continual stability or even improvement in childhood. This contrasts with the report by Moorcroft et al, but they were able to obtain follow up data in only one third (30 patients) of their original sample, potentially skewing their conclusions. ${ }^{8}$

In summary, we have affirmed that peak $\mathrm{V}_{2}$ is correlated with survival in CF and have shown that peak $\dot{\mathrm{V}}_{2}$ exhibits a measurable decline in children with CF. Although $\mathrm{FEV}_{1}$ is simpler to obtain and more reproducible, it fails to deliver the more comprehensive functional assessment offered by measurement of peak aerobic power. The decision whether or not to incorporate periodic peak $\dot{\mathrm{V}}_{2}$ determinations will rest with individual clinics and attending physicians, and will depend on availability of resources. Nevertheless, our findings support the introduction of this assessment as early

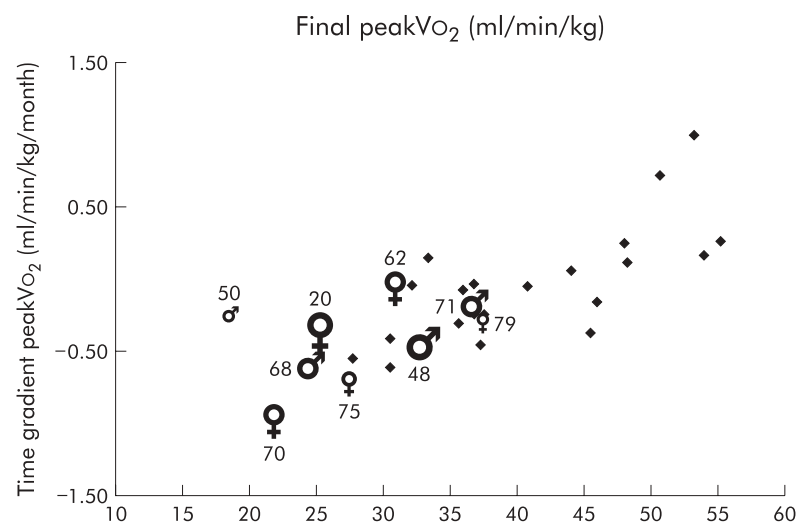

Figure 3 Plot of fitted slopes versus final peak $\mathrm{V}_{2}$ of each subject in the study group. The lung deaths are shown according to sex with the size of the symbol proportional to the age of the patient at commencement of the study. The number beside each event symbol is the number of months from the last test to the time of death. 
as possible, with repeat measurements at intervals. Only then will the true usefulness of peak $\dot{\mathrm{V}}_{2}$ as a prognostic index be realised.

\section{Authors' affiliations}

P Pianosi, J LeBlanc, Department of Pediatrics, Dalhousie University, Halifax, Canada

A Almudevar, Department of Biostatistics, University of Rochester, Rochester, NY, USA

\section{REFERENCES}

1 Godfrey S, Mearns M. Pulmonary function and response to exercise in cystic fibrosis. Arch Dis Child 1971;46:144-51.

2 Cerny FJ, Pullano TP, Cropp GJ, et al. Cardiorespiratory adaptations to exercise in cystic fibrosis. Am Rev Respir Dis 1982;126:217-20.

3 Cropp GJ, Pullano TP, Cerny FJ, et al. Exercise tolerance and cardiorespiratory adjustments at peak work capacity in cystic fibrosis. Am Rev Respir Dis 1982;126:211-6.

4 Marcotte JE, Canny GJ, Grisdale RK, et al. Effects of nutritional status on exercise performance in advanced cystic fibrosis. Chest 1986;90:375-9.

5 Marcotte JE, Grisdale RK, Levison H, et al. Multiple factors limit exercise capacity in cystic fibrosis. Pediatr Pulmonol 1986;2:274-81.

6 Lands LC, Heigenhauser GJ, Jones NL. Analysis of factors limiting maximal exercise performance in cystic fibrosis. Clin Sci 1992;83:391-7.

7 Nixon PA, Orenstein DM, Kelsey SF, et al. The prognostic value of exercise testing in patients with cystic fibrosis. N Engl J Med 1992;327:1785-8.

8 Moorcroft AJ, Dodd ME, Webb AK. Exercise testing and prognosis in adult cystic fibrosis. Thorax 1997;52:291-3.

9 Stanghelle JK, Michalsen H, Haanæs OC. Five-year follow-up of pulmonary function and oxygen uptake during exercise in 16 year old boys with cystic fibrosis. Acta Pædiatr 1992;81:527-31.

10 Moorcroft AJ, Dodd ME, Webb AK. Long-term change in exercise capacity, body mass, and pulmonary function in adults with cystic fibrosis. Chest 1997;111:338-43.
11 The Cystic Fibrosis Genotype-Phenotype Consortium. Correlation between genotype and phenotype in cystic fibrosis. N Engl J Med 1993;329:1308-13.

12 Selvadurai HC, McKay KO, Blimkie CJ, et al. The relationship between genotype and exercise tolerance in children with cystic fibrosis. Am J Respir Crit Care Med 2002:165:762-5.

13 Oga T, Nishimura K, Tsukino M, et al. Analysis of the factors related to mortality in chronic obstructive pulmonary disease. Am J Respir Crit Care Med 2003; 167:544-9.

14 Knudson RJ, Lebowitz MD, Holberg CJ, et al. Changes in the normal maximal expiratory flow-volume curve with growth and aging. Am Rev Respir Dis 1983; 127:725-34.

15 Moore DJ, Durie PR, Forstner GG, et al. The assessment of nutritional status in children. Nutrition Res 1985:5:797-9.

16 Nagelkerke NJD. A note on a general definition of the coefficient of determination. Biometrika 1991;78:691-2.

17 Sharma R, Florea VG, Bolger AP, et al. Wasting as an independent predictor of mortality in patients with cystic fibrosis. Thorax 2001;56:746-50.

18 Corey M, Edwards L, Levison $\mathrm{H}$, et al. Longitudinal analysis of pulmonary function decline in patients with cystic fibrosis. J Pediatr 1997;131:809-14.

19 Nixon PA, Orenstein DM, Kelsey SF. Habitual physical activity in children and adolescents with cystic fibrosis. Med Sci Sports Exerc 2001;33:30-5.

20 Boucher GP, Lands LC, Hay JA, et al. Activity levels and the relationship to lung function and nutritional status in children with cystic fibrosis. Am J Phys Med Rehabil 1997;76:311-5.

21 Britto MT, Garrett JM, Konrad TR, et al. Comparison of physical activity in adolescents with cystic fibrosis versus age-matched controls. Pediatr Pulmonol 2000;30:86-91.

22 Welsman JR, Armstrong N. Daily physical activity and blood lactate indices of aerobic fitness in children. Br J Sports Med 1992;26:228-32.

23 Bar-Or O. Pediatric sports medicine for the practitioner. New York: SpringerVerlag, 1983:101-4.

24 Bouchard C. Genetics of aerobic power and capacity. In: Malina RM, Bouchard C, eds. Sport and human genetics. Champaign, IL: Human Kinetics, 1986:59-88.

25 Santis G, Osborne L, Knight RA, et al. Linked marker haplotypes and the $\Delta$ F508 mutation in adults with mild pulmonary disease and cystic fibrosis. Lancet 1990;335:1426-9.

\section{LUNG ALERT}

\section{Decreased pulmonary lactoferrin activity facilitates Pseudomonas biofilm formation in $\mathrm{CF}$}

$\Delta$ Rogan MP, Taggart CC, Greene CM, et al. Loss of microbiological activity and increased formation of biofilm due to decreased lactoferrin activity in patients with cystic fibrosis. J Infect Dis 2004;190:1245-53

a actoferrin is an important antimicrobial protein in the airways. In this study lactoferrin activity and Pseudomonas biofilm formation were investigated in sputum and bronchoalveolar lavage (BAL) fluid from age and genotype matched cystic fibrosis (CF) patients with and without $P$ aeruginosa colonisation $(\mathrm{n}=20)$.

In $P$ aeruginosa positive subjects the sputum lactoferrin concentration, corrected for sputum neutrophils, was significantly lower $(p<0.003)$ and cathepsin activity significantly increased $(p<0.012)$. Degradation of lactoferrin was observed in the presence of BAL fluid from these patients and prevented using specific cathepsin inhibitors. Lactoferrin, once cleaved by cathepsin (B, L or S), showed significantly reduced activity against $P$ aeruginosa $(\mathrm{p}=0.033)$. In addition, lactoferrin was found significantly to inhibit Pseudomonas biofilm formation $(p<0.001)$, but not after cleavage with cathepsins. In keeping with these findings, sputum from the $P$ aeruginosa positive subjects had significantly reduced ability to inhibit biofilm formation compared with non- $P$ aeruginosa sputum samples $(\mathrm{p}<0.01)$.

This study shows that increased cathepsin activity in CF patients with sputum $P$ aeruginosa results in degradation of lactoferrin. The consequence is a loss of antimicrobial activity against $P$ aeruginosa and of the host ability to prevent biofilm formation. This mechanism may have an important role in the development of colonisation with $P$ aeruginosa in CF with resulting clinical deterioration. 